\title{
СОСТАВ И СТРУКТУРА СМОЛИСТЫХ КОМПОНЕНТОВ ЛЕГКОЙ И ТЯЖЕЛЫХ НЕФТЕЙ
}

Герасимова Наталья Николаевна',

dm@ipc.tsc.ru

\author{
Чешкова Татьяна Викторовна', \\ chtv12@mail.ru
}

\section{Голушкова Евгения Борисовна², egol74@mail.ru}

\section{Сагаченко Татьяна Анатольевна', dissovet@ipc.tsc.ru}

\author{
Мин Раиса Сергеевна', \\ Igosn@ipc.tsc.ru \\ 1 Институт химии нефти Сибирского отделения Российской академии наук, \\ Россия, 634055, г. Томск, пр. Академический, 4. \\ 2 Национальный исследовательский Томский политехнический университет, \\ Россия, 634050, г. Томск, пр. Ленина, 30.
}

Актуальность работы обусловлена отсутствием сравнительной характеристики состава и строения смол нефтей различной химической природы, так как особенности структуры смолистых компонентов оказывают существенное влияние на глубину их превращения в легкие углеводороды для производства светлых нефтепродуктов. Особое значение работы в этом направлении получили в последнее время из-за неуклонного роста в составе разведанных и извлекаемых запасов тяжелых высоковязких нефтей, которые отличаются от традиционных нефтей высоким содержанием высокомолекулярных гетероатомных соединений. Цель: сравнительное изучение состава, структуры и особенностей строения основных структурных блоков молекул и химического состава азоторганических оснований смолистых компонентов легкой и тяжелых нефтей.

Методы: селективная химическая деструкция сульфидных и эфирных связей, элементный и структурно-групповой анализы, жидкостно-адсорбционная хроматография, криоскопия в бензоле, ЯМР'Н-спектроскопия, хроматомасс-спектрометрия.

Результаты. Проведен сравнительный анализ состава и структуры смолистых компонентов легкой и тяжелых нефтей. Определены сходства и различия их структурно-группового состава, строения азотистых соединений основного характера и структурных блоков, связанных в молекулах смол С-О И C-S связями. Установлено, что смолистые компоненты тяжелых нефтей отличаются большими общими размерами средних молекул за счет числа связанных воедино структурных единиц (1,79-1,86 против 1,25), имеющих более крупные средние размеры полиареновых ядер (число ароматических циклов 2,36-2,43 против 1,57); большее число алициклических фрагментов, сконденсированных с ароматическим ядром молекул (количество атомов С, находящихся в ?-положении к ароматическим циклам 4,56-4,75 против 3,42), и большую распространенность длинных алкильных заместителей $(2,42-2,59$ против 1,97). К наиболее распространенным «связанным» фрагментам макромолекул исследуемых смол относятся н-алканы, циклогексаны, прегнаны, холестаны, хейлантаны и гопаны. Особенностью молекул смол тяжелых нефтей является присутствие в составе их «эфиросвязанных» фрагментов полициклических ароматических углеводородов и гетероорганических соединений, а особенностью смол легкой нефти - присутствие в составе «серосвязанных» фрагментов полициклоалканов, этиловых эфиров н-алкановых кислот, алифатических спиртов и бициклических сульфидов. Смолы тяжелых нефтей характеризуются более высоким суммарным выходом азоторганических оснований (38,4-40,8 против 26,0 \%), в составе которых доминируют соединения, осаждаемые в виде нерастворимых хлористоводородных солей (36,5-37,6 против 10,9%).

\section{Ключевые слова:}

Нефть, смолы, структурно-групповой состав, селективная химическая деструкция, фрагменты, связанные алифатическими С-О и С-S мостиками, азоторганические основания, состав.

\section{Введение}

В данной работе продолжены исследования, направленные на расширение представлений о составе и структуре смолисто-асфальтеновых компонентов нефти [1-10]. В ней приведена характеристика смол легкой малосмолистой и тяжелых высокосмолистых нефтей. Интерес к таким работам обусловлен тем, что в последнее время в объеме добываемого углеводородного сырья резко возросла доля тяжелых и сверхтяжелых нефтей, в составе которых более 30 \% приходится на смолистые вещества [11-13], содержащие в структуре от 70 до
90 \% всех гетероорганических соединений, присутствующих в нефтяных системах [14]. Если проблемы добычи таких нефтей в определенной степени решены или решаются, то существующие технологии не приспособлены к глубокой переработке данных типов углеводородных ресурсов. Наличие в составе смол соединений серы, кислорода, азота и, особенно, азоторганических оснований оказывает отрицательное влияние на процессы переработки нефти, потребительские свойства товарных нефтепродуктов и уровень загрязнения окружающей среды [15-25]. 
Необходимым условием для разработки новых технических решений в области глубокой переработки нетрадиционного углеводородного сырья является накопление информации о составе и строении смолистых компонентов нефтей различного типа, так как особенности структурных характеристик смол оказывают существенное влияние на глубину и направленность их переработки [26].

Цель работы: сравнительное изучение состава, структуры и особенностей строения основных структурных блоков молекул и химического состава азоторганических оснований смолистых компонентов легкой и тяжелых нефтей.

\section{Методики экспериментов и характеристики исследуемых веществ}

Исследовали смолы легкой малосмолистой (тип I - метано-нафтеновая) и тяжелых высокосмолистых (тип II - нафтено-метановая и тип III - нафтеновая) нефтей (табл. 1). Смолы выделяли из деасфальтенизатов соответствующих нефтей по методике [27].

Содержание $\mathrm{C}, \mathrm{H}, \mathrm{N}$ и $\mathrm{S}$ определяли с использованием анализатора «Vario EL Cube», $\mathrm{O}$ - по разности между $100 \%$ и содержанием элементов С, Н, $\mathrm{N}, \mathrm{S}$. Содержание основного азота $\left(\mathrm{N}_{\text {осн }}\right)$ определяли с применением метода неводного потенциометрического титрования [28].

Для характеристики полученных образцов смол использовали метод структурно-группового анализа (СГА) [29], в основу которого положены данные элементного анализа, значения средних молекулярных масс и относительное содержание протонов в различных структурных группах молекул соединений [30], а также метод разрушения мостиковых связей C-O и C-S в их молекулах [3].

Молекулярные массы измеряли с помощью криоскопии в бензоле [27]. Спектры ПМР записывали с применением ЯМР-Фурье спектрометра «AVANCE AV 300» фирмы «Bruker» в растворах $\mathrm{CDCl}_{3}$.

Таблица 1. Характеристика нефтей и смол

Table 1. Properties of oils and resins

\begin{tabular}{|c|c|c|c|c|c|c|c|c|c|}
\hline \multirow[b]{2}{*}{$\begin{array}{l}\text { Образец } \\
\text { Sample }\end{array}$} & \multirow{2}{*}{ 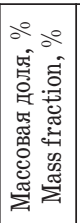 } & \multirow{2}{*}{ 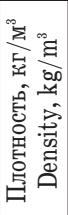 } & \multirow{2}{*}{ 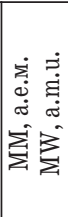 } & \multicolumn{6}{|c|}{$\begin{array}{c}\text { Массовая доля, \% } \\
\text { Mass fraction, \% }\end{array}$} \\
\hline & & & & $\mathrm{C}$ & $\mathrm{H}$ & S & $\mathrm{N}$ & $\begin{array}{l}\mathrm{N}_{\text {och }} \\
\mathrm{N}_{\text {bas }}\end{array}$ & 0 \\
\hline $\begin{array}{c}\text { Нефть I } \\
\text { Oil I }\end{array}$ & 100,0 & 867 & 273 & 83,27 & 11,02 & 1,05 & 0,21 & 0,03 & 4,15 \\
\hline $\begin{array}{l}\text { Смолы } \\
\text { Resins }\end{array}$ & 8,8 & - & 480 & 80,50 & 9,74 & 3,53 & 0,56 & 0,25 & 5,42 \\
\hline $\begin{array}{c}\text { Нефть II } \\
\text { Oil II }\end{array}$ & 100,0 & 978 & - & 82,75 & 12,19 & 3,77 & 0,67 & 0,12 & 0,50 \\
\hline $\begin{array}{l}\text { Смолы } \\
\text { Resins }\end{array}$ & 18,4 & - & 866 & 80,10 & 9,05 & 5,02 & 1,14 & 0,44 & 4,25 \\
\hline $\begin{array}{c}\text { Нефть III } \\
\text { Oil III }\end{array}$ & 100 & 971 & 365 & 82,03 & 12,12 & 1,78 & 0,64 & 0,19 & 3,24 \\
\hline $\begin{array}{l}\text { Смолы } \\
\text { Resins }\end{array}$ & 22,1 & - & 877 & 81,14 & 9,35 & 2,51 & 1,08 & 0,55 & 5,37 \\
\hline
\end{tabular}

Рассчитаны следующие параметры: $\mathrm{m}_{\mathrm{a}}, \mathrm{K}_{0}{ }^{*}$, $\mathrm{K}_{\mathrm{a}}{ }^{*}, \mathrm{~K}_{\mathrm{H}}{ }^{*}, \mathrm{C}_{\text {п }}{ }^{*}, \mathrm{C}_{\alpha}{ }^{*}$ и $\mathrm{C}_{\gamma}{ }^{*}$ - число структурных блоков в средней молекуле, общее количество колец, количество ароматических и нафтеновых циклов в структурном блоке, количество углеродных атомов в парафиновых фрагментах структурного блока, количество углеродных атомов, находящихся в $\alpha$-положении к ароматическим ядрам и в терминальных метильных группах, не связанных с ними, соответственно.

Для разрыва С-О связей в молекулах смол использовали трибромид бора, для разрыва C-S связей - борид никеля [3].

Азотистые основания (A0) извлекали из гексановых растворов смол в соответствии с методикой [4], позволяющей дифференцировать основные соединения по молекулярной массе в процессе выделения. В результате получены концентраты высокомолекулярных оснований $(\kappa-1$ и $\mathrm{K}-2)$ и низкомолекулярных оснований (К-3).

Жидкие продукты селективной химической деструкции и концентраты низкомолекулярных АО исследовались с использованием хроматомассспектрометра высокого разрешения с двойной фокусировкой DFS «Thermo Fisher Scientific». Идентификацию индивидуальных соединений осуществляли компьютерным поиском в библиотеке Национального института стандартов и по литературным данным [3, 4].

Для проведения аналитических работ использовали приборную базу Центра коллективного пользования Томского научного центра СО РАН.

\section{Результаты и их обсуждение}

По данным табл. 2, смолы легкой малосмолистой нефти (тип I) состоят из одноблочных молекул $\left(\mathrm{m}_{\mathrm{a}}=1,25\right)$.

Таблица 2. Средние структурные параметры смол нефтей различных типов

Table 2. Average structural parameters of resins of various types oils

\begin{tabular}{|c|c|c|c|}
\hline \multirow{2}{*}{$\begin{array}{c}\text { Параметры среднего } \\
\text { структурного блока } \\
\text { Parameters of average } \\
\text { structural block }\end{array}$} & \multicolumn{3}{|c|}{ Смолы/Resins } \\
\cline { 2 - 4 } & \multicolumn{3}{|c|}{ Тип нефти/Oil type } \\
\cline { 2 - 4 } & $\mathrm{I}$ & $\mathrm{II}$ & $\mathrm{III}$ \\
\hline $\mathrm{m}_{\mathrm{a}}$ & 1,25 & 1,86 & 1,79 \\
\hline $\mathrm{K}_{\mathrm{o}}{ }^{*}$ & 4,09 & 5,53 & 5,46 \\
\hline $\mathrm{K}_{\mathrm{a}}{ }^{*}$ & 1,57 & 2,43 & 2,36 \\
\hline $\mathrm{K}_{\mathrm{H}}{ }^{*}$ & 2,52 & 3,10 & 3,10 \\
\hline $\mathrm{C}^{*}$ & 25,77 & 31,10 & 33,19 \\
\hline $\mathrm{C}_{\mathrm{a}}{ }^{*}$ & 7,06 & 9,75 & 9,67 \\
\hline $\mathrm{C}_{\mathrm{H}}{ }^{*}$ & 10,26 & 12,55 & 12,68 \\
\hline $\mathrm{C}_{\mathrm{I}}{ }^{*}$ & 8,45 & 8,79 & 10,84 \\
\hline $\mathrm{C}_{\alpha}{ }^{*}$ & 3,42 & 4,75 & 4,56 \\
\hline $\mathrm{C}_{\gamma}{ }^{*}$ & 1,97 & 2,42 & 2,59 \\
\hline $\mathrm{N}^{*}$ & 0,15 & 0,38 & 0,38 \\
\hline $\mathrm{S}^{*}$ & 0,46 & 0,80 & 0,45 \\
\hline $0^{*}$ & 1,30 & 1,24 & 1,64 \\
\hline
\end{tabular}

В качестве структурных блоков выступают тетрациклические системы $\left(\kappa_{0} *=4,09\right)$, состоящие 
из одного двух ароматических $\left(\kappa_{\mathrm{a}}^{*}=1,57\right)$ и двух-трех нафтеновых $\left(\mathrm{K}_{\text {н }}^{*}=2,52\right)$ циклов, обрамленные алкильными заместителями. Количество атомов углерода, связанных с заместителями в ароматическом ядре молекул $\left(\mathrm{C}_{\alpha}{ }^{*}\right)$, меньше четыpex, что указывает на его крайнее расположение в нафтеноароматической системе [31]. На структурный блок средних молекул смол легкой нефти приходится 8,45 парафиновых атомов углерода $\left(\mathrm{C}_{\text {п }}^{*}\right)$. Число метильных групп в составе заместителей, не присоединенных к ароматическому ядру $\left(\mathrm{C}_{\gamma}{ }^{*}\right)$, меньше двух $(1,97)$. Это свидетельствует о линейном или слаборазветвленном характере преобладающей части имеющихся в молекулах алифатических цепей и малой распространенности относительно длинных линейных алкильных заместителей.

Смолистые компоненты тяжелых нефтей по структурно-групповым характеристикам заметно отличаются от смол нефти типа I. Средние молекулы смол нефтей типов II и III преимущественно состоят из двух блоков $\left(\mathrm{m}_{\mathrm{a}}=1,79\right.$ и 1,86$)$, которые имеют большие общие размеры $(\mathrm{C} * 31,10$ и $33,19$ против 25,77$)$ и обогащены ароматическими $\left(\mathrm{K}_{\mathrm{a}}^{*}=2,36\right.$ и 2,43 против 1,57$)$ и нафтеновыми $\left(\kappa_{\mathrm{H}}{ }^{*}=3,10\right.$ и 3,10 против 2,52$)$ структурами. Значение параметра $\mathrm{C}_{\alpha}$ * в смолах тяжелых нефтей выше 4,0 свидетельствует о внутреннем расположении ароматических циклов в их нафтеноароматических системах. Алкильные заместители в рассматриваемых блоках содержат 8,79 и 10,84 атомов углерода. Значения параметра $\mathrm{C}_{\gamma}$ * больше $2(2,42$ и $2,59)$, отражающего содержание терминальных метильных групп, указывают на большую распространенность в структуре молекул смол тяжелых нефтей относительно длинных разветвленных и/или слаборазветвленных парафиновых цепей.

Данные по содержанию гетероатомов (табл. 2) свидетельствуют, что в структуре смол всех типов нефтей наиболее широко представлены серо- и кислородсодержащие блоки. В молекулах смолистых веществ нефти типа I присутствуют $46 \%$ серосодержащих структурных блоков $(\mathrm{S} *=0,46)$ и $30 \%$ структурных блоков, содержащих 2 атома кислорода $(0 *=1,30)$. В молекулах смол нефтей II и III типов на долю серосодержащих блоков приходится 80 и $45 \%$ (S*=0,80 и 0,45$)$ соответственно, а 24 и $64 \%$ структурных блоков содержат 2 атома кислорода $(0 \%=1,24$ и $1,64 \%)$. Азот входит в структуру $15 \%$ блоков в случае смолистых веществ нефти типа I $(\mathrm{N} *=0,15)$ и $38 \%$ блоков в случае смолистых молекул тяжелых нефтей II и III типов $\left(\mathrm{N}^{*}=0,38\right.$ и 0,38$)$.

Из анализа литературных данных [3, 5, 9, 32 , 33] следует, что атомы серы и кислорода могут находиться в структуре молекул исследуемых смол как в циклах, так и в заместителях. Нельзя исключать присутствие таких атомов в мостиках, соединяющих циклы. Повышенная концентрация атомов азота отмечена в полициклических блоках молекул смол.

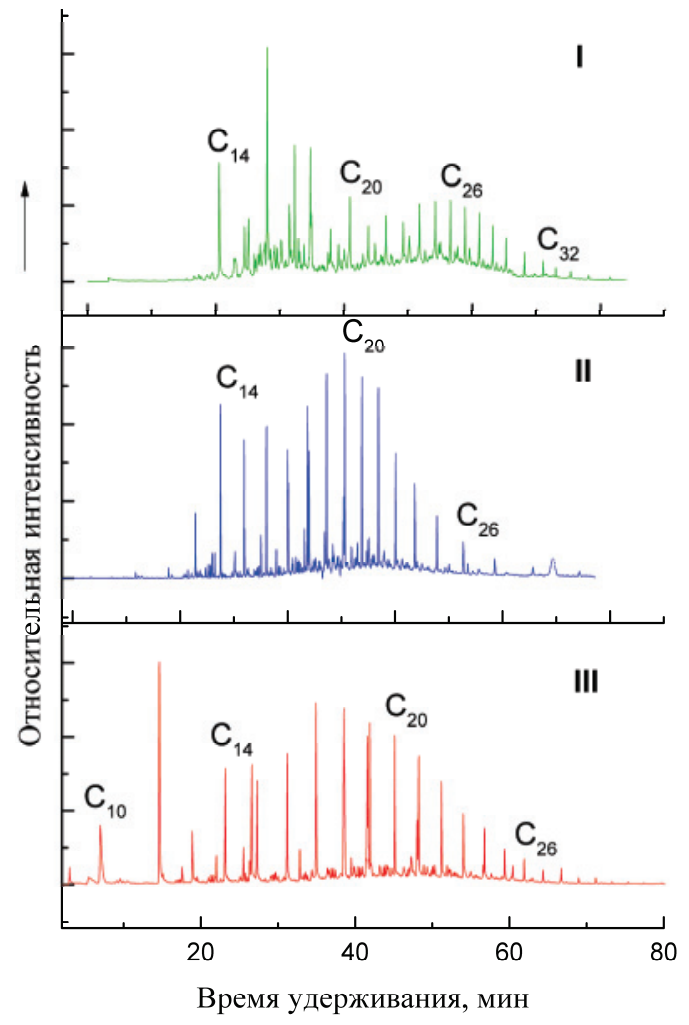

Рис.1. Распределение н-алканов в продуктах разрушения эфирных связей в молекулах смол легкой (I) и тяжельх (II, III) нефтей при сканировании по иону $\mathrm{m} / z$ 71. Цифры $y$ $\mathrm{C}_{10}-\mathrm{C}_{36}-$ количество атомов углерода

Fig. 1. Distribution of n-alkanes in the products of ether bond destruction in the molecules of resins of the light oil (I) and the heavy oils (II, III) scanned at $\mathrm{m} / \mathrm{z} 71$. Index numbers of $C_{10}-C_{36}$ are the number of carbon atoms

По данным ГХ-МС анализа среди соединений, связанных в молекулах смол исследованных нефтей эфирныли лостикали, присутствуют н-алканы и алканы разветвленного строения, представленные монометилзамещенными структурами, различающиеся положением замещающего радикала и изопреноидами $(2,6,10$-триметилалканами, пристаном и фитаном), пяти- и шестичленные насыщенные циклические алканы с алкильными заместителями, стераны, гопаны, фенилалканы, фитанилбензолы, алкилбензолы с положением заместителей у атомов углерода 1-4 [5, 9]. При сходном качественном составе насыщенных и ароматических углеводородов (УВ) смолы легкой и тяжелых нефтей различаются по молекулярно-массовому распределению отдельных представителей «эфиросвязанных» фрагментов. Согласно рис. 1 , на котором в качестве примера приведено распределение н-алканов в продуктах разрушения С-O связей простых и/или сложных эфиров в молекулах изученных смол, следует, что отличительной особенностью этого типа фрагментов в молекулах смол тяжелых нефтей является меньшее число атомов углерода в цепи. Различия наблюдаются и в молекулярно-массовом распределении моноаренов, соединенных между собой через эфирные мостики. В молекулах смол неф- 
ти типа I эти фрагменты характеризуются большим числом атомов углерода в алкильном заместителе налкилбензолов, алкилметил-, алкилдиметил- и алкилтетраметилбензолов.

Особенностью молекул смол тяжелых нефтей является также присутствие в составе их «эфиросвязанных» фрагментов низкомолекулярных стеранов, трициклических терпанов, $\mathrm{C}_{0}-\mathrm{C}_{4}$ нафталинов, $\mathrm{C}_{0}-\mathrm{C}_{2}$ фенантренов, $\mathrm{C}_{2}-\mathrm{C}_{5}$ бензотиофенов, $\mathrm{C}_{0}-\mathrm{C}_{4}$ дибензотиофенов и алифатических спиртов нормального строения состава $\mathrm{C}_{12}, \mathrm{C}_{14}, \mathrm{C}_{16}, \mathrm{C}_{18}$ [9]. Нефть типа II выделяется также наличием «эфиросвязанных» алифатических кислот состава $\mathrm{C}_{6}-\mathrm{C}_{16}$ и бициклических терпеноидных сульфидов состава $\mathrm{C}_{13}-\mathrm{C}_{22}$. Среди «эфиросвязанных» фрагментов молекул смол нефти I полициклические ароматические УВ (АУ) и гетероорганические соединения (ГОС) не обнаружены.

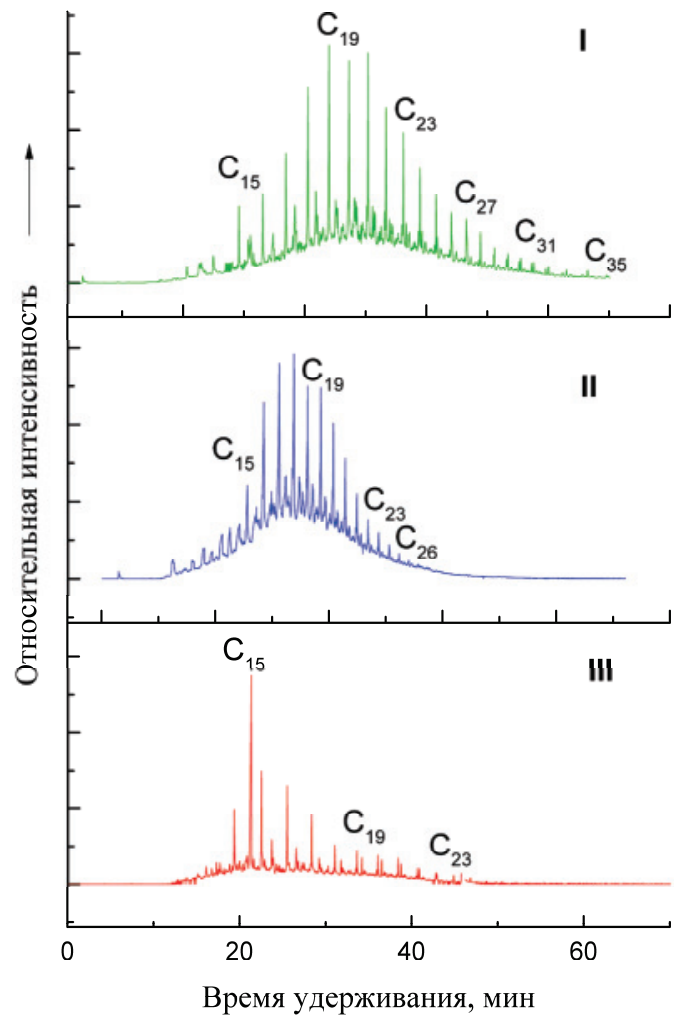

Pис. 2. Распределение алкилииклогексанов в продуктах химиче ской деструкиии C-S связей в молекулах слол легкой (I) и тажелых (II, III) нефтей при сканировании по иону

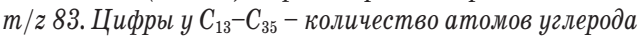

Fig. 2. Distribution of alkylcyclohexanes in the products of C-S bond cleavage in the molecules of resins of the light oil (I) and the heavy oils (II, III) scanned at $\mathrm{m} / \mathrm{z}$ 83. Index numbers of $\mathrm{C}_{13}-\mathrm{C}_{35}$ are the number of carbon atoms

Едиными «серосвязанными» фрагментами в молекулах смол всех типов нефтей являются н-алканы, монометилзамещенные алканы, различающиеся положением замещающего радикала, изопреноиды (2,6,10-триметилалканы, пристан и фитан), алкилциклопентаны, алкилциклогексаны, фенилалканы, моноарены и одноосновные алифа- тические кислоты. Как и в случае «эфиросвязанных» структур, выделяются «серосвязанные» фрагменты смол малосмолистой нефти. Алканы и моноциклоалканы (рис. 2), связанные в их молекулах через сульфидные мостики, характеризуются более широким молекулярно-массовым распределением, а моноарены - более длинным алкильным заместителем.

Важной особенностью молекул смол нефти I является присутствие в составе их «серосвязанных» фрагментов стеранов, три- и пентациклических терпанов, близких по составу к «эфиросвязанныл» аналогам, и более широкого набора гетероорганических соединений [5]. Среди последних, кроме алкановых кислот, установлены этиловые эфиры алкановых кислот, алифатические спирты и бициклические сульфиды. Этот тип сероорганических соединений идентифицирован также в составе «серосвязанных» фрагментов в молекулах смол тяжелой нафтено-метановой нефти.

Отличительной чертой смол этого типа нефти является наличие в их структуре "серосвязанных" $\mathrm{C}_{0}-\mathrm{C}_{5}$ нафталинов, $\mathrm{C}_{0}-\mathrm{C}_{4}$ фенантренов и $\mathrm{C}_{0}-\mathrm{C}_{4}$ дибензотиофенов.

Наличие идентифицированных в структуре исследуемых смол нормальных алканов, циклогексанов, прегнанов и стеранов, хейлантанов и гопанов отмечено также в составе продуктов термолиза смол тяжелой нефти месторождения Усинское [34] и асфальтита Ивановского месторождения [35]. Следовательно, весь спектр углеводородов, установленных в продуктах химической деструкции смолистых веществ легкой и тяжелой нефтей, является неотъемлемой частью строительных блоков молекул их смол. Различия в составе структурных фрагментов молекул смол, вероятнее всего, связаны с особенностями состава и строения исходного органического вещества нефти.

В продуктах химической деструкции смолистых веществ исследованных нефтей не были идентифицированы азотсодержащие соединения. «Связанные» азоторганические соединения нейтрального и основного характера не были определены и в структуре асфальтеновых веществ этих нефтей [3, 36]. Совокупность этих данных подтверждает предположение о преимущественном присутствии этих соединений в конденсированных полициклических блоках молекул смол и асфальтенов.

Из результатов, приведенных в табл. 3, следует, что тип нефти влияет на количество выделенных из смол АО и характер их распределения по соответствующим концентратам.

Так, суммарный выход АО из смол тяжелых нефтей существенно выше (38,4 и 40,8 мас. \%) их выхода из смол легкой нефти (26,0 мас. \%). Во всех случаях большую часть выделенных соединений составляют высокомолекулярные компоненты К-1 и К-2. При этом в смолах тяжелых нефтей преобладают компоненты К-I (35,6 и 37,6 мас. \% для нефтей II и III типов соответственно), а в смолах легкой нефти количество высокомолекуляр- 
ных компонентов $\mathrm{K}-1$ (10,9 мас. \%) сопоставимо с содержанием компонентов $\mathrm{K}-2(13,2$ мас. \%). Хотя содержание экстрагируемых соединений K-3 в составе всех исследуемых смол незначительно, в смолах легкой нефти их несколько больше (1,9 мас. \%), чем в смолах нефтей типов II $(1,3$ мac. $\%)$ и III $(1,0$ мac. $\%)$.

Таблица 3. Характеристика азоторганических оснований смол нефтей различных типов

Table 3. $\quad$ Properties of organic nitrogen bases from resins of various types oils

\begin{tabular}{|c|c|c|c|c|c|}
\hline $\begin{array}{l}\text { Смолы } \\
\text { Resins }\end{array}$ & $\begin{array}{l}\text { Концен- } \\
\text { трат } \\
\text { Concen- } \\
\text { trate }\end{array}$ & $\begin{array}{c}\text { Массовая } \\
\text { доля } \\
\text { Mass frac- } \\
\text { tion, \% }\end{array}$ & $\begin{array}{l}\text { MM, } \\
\text { a.e.M. } \\
\text { MW, } \\
\text { a.m.u. }\end{array}$ & $\begin{array}{c}\text { Массовая } \\
\text { доля } \mathrm{N}_{\text {осн }} \\
\text { Mass frac- } \\
\text { tion } \mathrm{N}_{\text {bas }}, \%\end{array}$ & $\begin{array}{c}\text { Доля } \mathrm{N}_{\text {осн }} \\
\text { смол } \\
\text { Fraction of } \\
\mathrm{N}_{\text {bas }} \text { resins, \% }\end{array}$ \\
\hline \multirow{3}{*}{$\begin{array}{c}\text { нефти I ти- } \\
\text { па } \\
\text { I type oil }\end{array}$} & $\begin{array}{l}\mathrm{K}-1 / \mathrm{C}-1 \\
\end{array}$ & 10,9 & 1018 & 0,73 & 31,8 \\
\hline & $\mathrm{K}-2 / \mathrm{C}-2$ & 13,2 & 607 & 0,72 & 38,1 \\
\hline & K-3/C-3 & 1,9 & 383 & 1,86 & 14,4 \\
\hline \multirow{3}{*}{$\begin{array}{l}\text { нефти II } \\
\text { типа } \\
\text { II type oil }\end{array}$} & K-1/C-1 & 36,5 & 833 & 0,87 & 70,4 \\
\hline & K-2/C-2 & 0,6 & 636 & 0,99 & 1,3 \\
\hline & K-3/C-3 & 1,3 & 383 & 2,06 & 6,2 \\
\hline \multirow{3}{*}{$\begin{array}{l}\text { нефти III } \\
\text { типа } \\
\text { III type oil }\end{array}$} & K-1/C-1 & 37,6 & 844 & 1,17 & 79,9 \\
\hline & K-2/C-2 & 2,2 & 519 & 0,90 & 3,6 \\
\hline & K-3/C-2 & 1,0 & 392 & 1,31 & 2,4 \\
\hline
\end{tabular}

Различаются смолы и по относительному содержанию $\mathrm{N}_{\text {осн }}$ в структуре выделенных соединений. В смолах нефтей II и III типов основное его количество $(70,4$ и 79,9 отн. \%) входит в структуру компонентов $\mathrm{K}-1$. На долю компонентов К-2 приходится 1,3 и 3,6 отн. \%, на долю компонентов К-3 - 6,2 и 2,4 отн. \% В случае смол легкой нефти доля $\mathrm{N}_{\text {осн }}$ в структуре компонентов $\mathrm{K}-1$ существенно ниже $(31,8$ отн. $\%)$, а доля $\mathrm{N}_{\text {осн }}$ в структуре компонентов К-2 и К-3 существенно выше $(38,1$ и 14,4 отн. \%). Такое отличие в распределении функционального азота может быть связано с особенностями строения азоторганических оснований в молекулах смолистых компонентов нефтей.

По данным ГХ-МС анализа в составе низкомолекулярных оснований $\mathrm{K}-3$ идентифицированы $\mathrm{C}_{2}-\mathrm{C}_{3}$ хинолины и $\mathrm{C}_{2}-\mathrm{C}_{5}$ бензохинолины, преимущественно представленные метилзамещенными структурами. Это доказывает вид их масс-спектров: молекулярный ион характеризуется максимальной интенсивностью, для ионов $[\mathrm{M}-\mathrm{H}]^{+} / \mathrm{M}^{+}$отмечено крайне низкое соотношение и нет пиков перегруппировочных ионов [16]. Среди алкилхинолинов однозначно установлены 2,3,4-триметил- и $2,4,6$-триметилхинолины, среди бензохинолинов 2,4-диметилбензо(h)- и 2,4,6-триметилбензо(h)хинолины. Отличительной чертой низкомолекулярных АО смол тяжелых высокосернистых нефтей является присутствие в их составе гибридных структур - алкилзамещенных тиофенохинолинов и бензотиофенохинолинов.

\section{Заключение}

Единый подход к структурному исследованию смол нефтей разных типов позволил изучить особенности строения их молекул и выявить основные черты их сходства и различия. На основании проведенного сопоставительного анализа установлено, что:

- смолы тяжелых нефтей характеризуются большими общими размерами молекул; большим числом связанных воедино структурных единиц $(1,79-1,86$ против 1,25$)$; большими размерами полиареновых ядер, расположенных внутри нафтеноароматической системы (число ароматических циклов 2,36-2,43 против 1,57); более развитым алициклическим обрамлением ароматического ядра молекул (количество атомов C, находящихся в $\alpha$-положении к ароматическим циклам $4,56-4,75$ против 3,42 ) и большим числом длинных алкильных заместителей (2,42-2,59 против 1,97$)$;

- среди «серо- и эфиросвязанных» соединений в молекулах смол легкой и тяжелых нефтей присутствуют нормальные и разветвленные алканы, фенилалканы, алкилциклопентаны, алкилциклогексаны, моно-, би-, три- и тетраалкилбензолы;

- особенностью молекул смол тяжелых нефтей является присутствие в составе их «эфиросвязанных» фрагментов полициклических ароматических углеводородов и гетерооргнанических соединений, а особенность смол легкой нефти - присутствие в составе «серосвязанных» фрагментов полициклоалканов, этиловых эфиров н-алкановых кислот, алифатических спиртов и бициклических сульфидов;

- смолы тяжелых нефтей характеризуются более высоким суммарным выходом азотистых оснований $(38,4-40,8$ против 26,0 \% ), в составе которых доминируют соединения, осаждаемые в виде нерастворимых хлористоводородных солей $(36,5-37,6$ против 10,9 \% ). Среди низкомолекулярных азотистых оснований исследуемых смол присутствуют алкилзамещенные хинолины и бензохинолины;

- особенностью азотистых оснований смол тяжелых высокосернистых нефтей является наличие в составе низкомолекулярных оснований значительного количества азотсеросодержащих структур, представленных алкилзамещенными тиофенохинолинами и бензотиофенохинолинам.

Результаты проведенного исследования расширяют представления о строении нефтяных смол и могут быть использованы при модернизации существующих и создании новых способов глубокой переработки углеводородного сырья. 


\section{СПИСОК ЛИТЕРАТУРЫ}

1. Свириденко Н.Н., Кривцов Е.Б., Головко А.К. Изменение структуры молекул смол и асфальтенов природного битума в процессе термокрекинга / Химия в интересах устойчивого развития. - 2018. - Т. 26. - № 1. - С. 193-201.

2. Антипенко В.Р., Каюкова Г.П., Абдрафикова И.М. Состав продуктов гидротермально-каталитической конверсии асфальтита Спиридоновского месторождения // Нефтехимия. - 2019. T. 59. - № 1. - C. 54-63.

3. Sergun V.P., Cheshkova T.V., Sagachenko T.A., Min R.S. Structural Units with Sulfur and Ether/Ester Bonds in Molecules of High- and Low-Molecular-Weight Asphaltenes of Usa Heavy Oil. Petroleum Chemistry, 2016, vol. 56, no. 1, pp. 10-15.

4. Химический состав нефти Крапивинского месторождения (сообщение 4) / Т.В. Чешкова, Н.Н. Герасимова, Т.А. Сагаченко, P.С. Мин // Известия Томского политехнического университета. Инжиниринг георесурсов. - 2017. - Т. 328. - № 8. - С. 6-15.

5. Состав и строение смолистых компонентов тяжелой нефти месторождения Усинское / Т.В. Чешкова, Е.Ю. Коваленко, Н.Н. Герасимова, Т.А. Сагаченко, Р.С. Мин // Нефтехимия. 2017. - Т. 57 - № 1. - С. 33-40.

6. Групповой состав углеводородов и гетероатомных соединений в продуктах ступенчатого термолиза асфальтенов нефти Усинского месторождения / Д.С. Корнеев, В.Н. Меленевский, Г.С. Певнева, А.К. Головко // Нефтехимия. - 2018. - Т. 58. № 2. - C. $130-136$.

7. Герасимова Н.Н., Сагаченко Т.А., Мин Р.С. Превращения азоторганических оснований смолистых компонентов нефти Крапивинского месторождения при термическом воздействии // Известия Томского политехнического университета. Инжиниринг георесурсов. - 2018. - Т. 329. - № 11. - С. 17-24.

8. Азотсодержащие основания смол тяжёлой нефти Усинского месторождения / Н.Н. Герасимова, А.С. Классен, Р.С. Мин, Т.А. Сагаченко // Химия в интересах устойчивого развития. 2016. - T. 24. - № 6. - C. 739-744.

9. Химическая природа масляных и смолисто-асфальтеновых компонентов природного битума Ашальчинского месторождения Татарстана / Т.А. Сагаченко, В.П. Сергун, Т.В. Чешкова, Е.Ю. Коваленко, Р.С. Мин // Химия твердого топлива. 2015. - № 6. - C. 12-18.

10. Characterization of heteroatom compounds in a crude oil and its saturates, aromatics resins, and asphaltenes (SARA) and non-basic nitrogen fractions analyzed by negative-ion electpospray ioniztoin fourier transform ion cyclotron resonance mass spectrometry / Q. Shi, D. Hou, K.H. Chung, Ch. Xu, S. Zhao, Y. Zhang // Energy and Fuels. - 2010. - V. 24. - № 4. - P. 2545-2553.

11. Камьянов В.Ф., Аксенов В.С., Титов В.И. Гетероатомные компоненты нефтей. - Новосибирск: Наука, 1983. - 238 с.

12. Resin from Liaohe Heavy Oil: Molecular Structure, Aggregation Behavior, and Effect on Oil Viscosity / T. Li, J. Xu, R. Zou, H. Feng, L. Li, J. Y. Wang, M.A.C. Stuart, X.H. Guo // Energy Fuels. - 2018. - V. 32. - № 1. - P. 306-313.

13. Щепалов А.А. Тяжелые нефти, газовые гидраты и другие перспективные источники углеводородного сырья. - Нижний Новгород: Нижегородский госуниверситет, 2012. - 93 с.

14. Гордадзе Г.Н. Углеводороды в нефтяной геохимии. Теория и практика. - М.: Российский государственный университет нефти и газа им. И.М. Губкина, 2015. - 559 с.

15. Transformation of nitrogen-containing compounds in atmospheric residue by hydrotreating / M. Liu, L.Z. Zhang, C. Zhang, S.H. Yuan, L.H. Duan // Korean Jounal of Chemical Engineering. - 2018. - V. 35. - № 2. - P. 375-382.

16. Prado G.H.C., Rao Y., De Klerk A. Nitrogen Removal from Oil: a Review // Energy Fuels. - 2017. - V. 31 - № 1. - P. 14-36.

17. Structure and Composition Changes of Nitrogen Compounds during the Catalytic Cracking Process and Their Deactivating Effect on Catalysts / X.B. Chen, Y.B. Liu, S.J. Li, X. Feng,
H.H. Shan, C.H. Yang // Energy Fuels. - 2017. - V. 31 - № 4. P. $3659-3668$.

18. Inductive Effect of Basic Nitrogen Compounds on Coke Formation During the Catalytic Cracking Process / X.B. Chen, T. Li, L. Xin, Y.Q. Yang, H.H. Shan, C. H. Yang // Catalysis Communications. - 2016. - V. 74. - P. 95-98.

19. Hydrodenitrogenation of Basic and Non-Basic Nitrogen-Containing Compounds in Coker Gas Oil / Q. Wei, S.C. Wen, X.J. Tao, T. Zhang, Y.S. Zhou, K. Chung, C.M. Xu // Fuel Processing Technology. - 2015. - V. 129. - P. 76-84.

20. Synergistic Process for High Nitrogen Content Feedstocks Catalytic-Cracking: A Case Study of Controlling the Reactions of Nitrogen Compounds in Situ / J. Zhang, H. Shan, X. Chen, W. Liu, C. Yang // Industrial and Engineering Chemistry Research. 2014. - V. 53. - № 14. - P. 5718-5727.

21. Дезактивирующее влияние азотистых соединений на превращения модельных углеводородов и реального сырья в условиях каталитического крекинга / Т.В. Бобкова, В.П. Доронин, О.В. Потапенко, Т.П. Сорокина, Н.М. Островский // Катализ в промышленности. - 2014. - № 2. - С. 40-45.

22. Влияние количественного содержания азотистых оснований в нефтепродуктах на термическую стабильность топлив / А.Я. Исаев, З.С. Аллахвердиев, В.И. Тагиев, Г.Ф. Мамедова, М.М. Исмайлова // Нефтепереработка и нефтехимия. Научнотехнические достижения и передовой опыт. - 2015. - № 2. C. 10-12.

23. Analysis of extractable basic nitrogen compounds in Buliangou subbituminous coal by positive-ion ESI FT-ICR MS / Jiao Kong, Xian-Yong Wei, Hong-Lei Yan, Zhan-Ku Li, Mei-Xia Zhao, Yan Li, Zhi-Min Zong // Fuel. - 2015. - V. 159. - P. 385-391.

24. Characterization of basic heteroatom-containing organic compounds in liquefaction residue from Sheunmu-Fugu subbituminous coal by positive-ion electrospray ionization Fourier transform ion cyclotron resonance mass spectrometry / Peng Li, Zhi-Min Zong, Zhan-Ku Li, Yu-Gao Wang, Fang-Jing Liu, Xian-Yong Wei // Fuel Processing Technology. - 2015. - V. 132. - P. 91-98.

25. Li S.J., Liu N.N. The transformation of basic nitrogen compounds in coker gas oil during catalytic cracking. Petroleum Science and Technology. - 2017. - V. 35. - № 11. - P. 1141-1145.

26. Взаимное влияние смол и масел нефти Усинского месторождения на направленность их термических превращений / Г.С. Певнева, Н.Г. Воронецкая, Д.С. Корнеев, А.К. Головко // Нестехимия. - 2017. - Т. 57. - № 4. - С. 479-486.

27. Современные методы исследования нефтей (справочно-методическое пособие) / под ред. А.И. Богомолова, М.Б. Темянко, Л.И. Хотынцевой. - Л.: Недра, 1984. - 431 с.

28. Okuno I., Latham D.R., Haines W.E. Type Analisis of Nitrogen in Petroleum Using Nonaqueous Potentiometric Titration and Litium Aluminum Hydride Reduction // Analitical Chemistry. 1965. - V. 37. - № 1. - P. 54-57.

29. Головко А.К., Камьянов В.Ф., Огородников В.Д. Высокомолекулярные гетероатомные компоненты нефтей Тимано-Печерского нефтегазоносного бассейна // Геология и геофизика. 2012. - T. 53. - № 12. - C. 1786-1795.

30. Fergoug T., Bouhadda Y. Determination of Hassi Messaoud asphaltene aromatic structure from H-1 \& C-13 NMR analysis // Fuel. - 2014. - V. 115. - № 1. - P. 521-526.

31. Химический состав нефтей Западной Сибири / под ред. Г.Ф. Большакова. - Новосибирск: Наука. Сибирское отделение, 1988. - 288 c.

32. Molecular Structure of Athabasca Asphaltene: Sulfide, Ether, and Ester Linkages / P. Peng, A.Morales-Izquierdo, A. Hogg, 0.P. Strauaz // Energy Fuels. - 1997. - V. 11. - № 5. P. 1171-1187.

33. The Organic Geochemistry of Asphaltenes and Occluded Biomarkers / L.R. Snowdon, J.K. Volkman, Z. Zhang, G. Tao, P. Liu // Organic Geochemistry. - 2016. - V. 91. - № 1. - P. 3-15. 
34. Головко А.К. Стуктурные превращения нефтенных смол и их фракций при термолизе // Нефтехимия. - 2018. - Т. 58. № 4. - С. 391-398.

35. Антипенко В.Р. Термические превращения высокосернистого природного асфальтита: Геохимические и технологические аспекты. - Новосибирск: Наука, 2013. - 184 с.
36. Химический состав нефти Крапивинского месторождения (сообщение 3) / В.П. Сергун, Т.В. Чешкова, Т.А. Сагаченко, Р.С. Мин // Известия Томского политехнического университета. Инжиниринг георесурсов. - 2017. - Т. 328. - № 7. C. $59-66$.

Поступила 28.08.2019 2.

\section{Информация об авторах}

Герасимова Н.Н., кандидат химических наук, старший научный сотрудник лаборатории гетероорганических соединений нефти Института химии нефти Сибирского отделения Российской академии наук.

Чешкова T.B., кандидат химических наук, научный сотрудник лаборатории гетероорганических соединений нефти Института химии нефти Сибирского отделения Российской академии наук.

Голушкова $\boldsymbol{E} . \boldsymbol{Б} .$, кандидат химических наук, доцент отделения естественных наук Школы базовой инженерной подготовки Национального исследовательского Томского политехнического университета.

Cагаченко T.A., доктор химических наук, ведущий научный сотрудник лаборатории гетероорганических соединений нефти Института химии нефти Сибирского отделения Российской академии наук.

Мuн P.C., доктор химических наук, заведующая лабораторией гетероорганических соединений нефти Института химии нефти Сибирского отделения Российской академии наук. 


\title{
COMPOSITION AND STRUCTURE OF RESIN COMPONENTS OF LIGHT OIL AND HEAVY OILS
}

\author{
Natalia N. Gerasimova',
}

dm@ipc.tsc.ru

\author{
Tatyana V. Cheshkova', \\ chtv12@mail.ru
}

\author{
Evgenia B. Goluhskova², \\ egol174@mail.ru
}

\section{Tатуаna A. Sagachenko', dissovet@ipc.tsc.ru}

\author{
Raisa S. Min', \\ lgosn@ipc.tsc.ru \\ ${ }^{1}$ Institute of Petroleum Chemistry of Siberian Branch of the Russian Academy of Sciences, \\ 4, Akademichesky Avenue, 634055, Tomsk, Russia. \\ 2 National Research Tomsk Polytechnic University, \\ 30, Lenin Avenue, 634050, Tomsk, Russia.
}

The relevance of the work is caused by the need to gather and summarize the information on composition and structure of resin components of oils of different chemical nature, since the structural characteristics of resins have a significant impact on the level of their conversion to light hydrocarbons used for production of light oil products. In recent times, the researches in this direction have taken a particular importance due to the steady growth of heavy high viscosity oils in explored and recoverable reserves. Heavy high viscosity oils differ from conventional oils in a high content of high molecular weight heteroatomic compounds.

The aim of the study is the comparative study of composition, structure and structural features of the main structural units of the molecules and chemical composition of the organic nitrogen bases of the resinous components of light and heavy oils.

Methods: elemental analysis, cryoscopy in benzene, liquid adsorption chromatography, selective chemical destruction of sulfide and ether bonds, 'H NMR spectroscopy, structural-group analysis, gas chromatography-mass spectrometry.

Results. The authors have carried out a comparative analysis of composition and structure of the resin components of the light oil and those of heavy oils and determined the similarities and differences of their structural-group composition and the composition of nitrogen-organic bases and fragments bound in the molecules of resins through ether and sulfide bridges. It was shown that resins of heavy oils are distinguished by large overall sizes of mean molecules due to the number of structural blocks bound together (1,79-1,86 againist 1,25). These structural blocks have larger average sizes of polyarene cores $(2,36-2,43$ againist 1,57), a greater number of alicyclic fragments condensed with an aromatic core of the molecules $(4,56-4,75$ againist 3,42), and an abundance of long alkyl substituents $(2,42-2,59$ againist 1,97). The most common «bound» fragments of macromolecules of the resins under study include $n$-alkanes, cyclohexanes, pregnanes, cholestanes, heylantanes, and hopanes. The peculiarity of resin molecules of heavy oils is the presence of polycyclic aromatic hydrocarbons and hetero-organic compounds in their "ether-bound" fragments, while resins of the light oil are characterized by the presence of polycycloalkanes, ethyl esters of $n$-alkanoic acids, aliphatic alcohols and bicyclic sulfides in their compositions. Resins of heavy oils are characterized by a higher total yield in organo-nitrogen bases (38,4-40,8 againist 26,0\%), where the prevalence of compounds precipitated as insoluble hydrochloride salts was revealed (36,5-37,6 againist 10,9\%).

\section{Key words:}

Oil, resins, structural group composition, selective chemical degradation,

fragments bound by aliphatic C-O and C-S bridges, organic nitrogen bases, composition.

\section{REFERENCES}

1. Sviridenko N.N., Krivtsov E.B., Golovko A.K. Change of structure of molecules of resins and asphaltenes of natural bitumen in the course of thermocracking. Chemistry for Sustainable Development, 2018, vol. 26, no. 1, pp. 193-201. In Rus.

2. Antipenko V.R., Kayukova G.P., Abdrafikova I.M. Composition of Hydrothermal-Catalytic Conversion Products of Asphaltite from the Spiridonovskoe Oilfield. Petroleum Chemistry, 2019, vol. 59 , no. 1, pp. 48-57.

3. Sergun V.P., Cheshkova T.V., Sagachenko T.A., Min R.S. Structural Units with Sulfur and Ether/Ester Bonds in Molecules of High- and Low-Molecular-Weight Asphaltenes of Usa Heavy Oil. Petroleum Chemistry, 2016, vol. 56, no. 1, pp. 10-15.

4. Cheshkova T.V., Gerasimova N.N., Sagachenko T.A., Min R.S. Chemical composition of petroleum from Krapivinskoe oilfield (message 4). Bulletin of the Tomsk Polytechnic University, Geo Assets Engineering, 2017, vol. 328, no. 8, pp. 6-15. In Rus.

5. Cheshkova T.V., Kovalenko E.Y., Gerasimova N.N., Sagachenko T.A., Min R.S. Composition and Structure of Resinous Components of Heavy Oil from the Usa Oilfield. Petroleum Chemistry, 2017, vol. 57, no. 1, pp. 31-38.

6. Korneev D.S., Melenevskii V.N., Pevneva G.S., Golovko A.K. Group Composition of Hydrocarbons and Hetero Compounds in Stepwise-Thermolysis Products of Asphaltenes from Usa 0il. Petroleum Chemistry, 2018, vol. 58, no. 3. pp. 179-185.

7. Gerasimova N.N., Sagachenko T.A., Min R.S. Transformation of Organic Nitrogen Bases in Resin Compontnts of Oil Recovered from the Krapivinsk Deposit at Termal Treatment. Bulletin of the Tomsk Polytechnic University. Geo Assets Engineering, 2018, vol. 329, no. 11, pp. 17-24. In Rus. 
8. Gerasimova N.N., Klassen A.S., Min R.S., Sagachenko T.A. Nitrogen-Containing Resin Bases from Heavy Oils of the Usinsk Deposit. Chemistry for Sustainable Development, 2016, vol. 24, no. 6, pp. 739-744. In Rus.

9. Sagachenko T.A., Sergun V.P., Cheshkova T.V., Kovalenko E.Y., Min R.S. Chemical Nature of the Oil and Tarry-Asphaltene Components of Natural Bitumen from the Ashal'chinsk Deposit in Tatarstan. Solid Fuel Chem., 2015, vol. 49, no. 6, pp. 349-355.

10. Shi Q., Hou D., Chung K.H., Xu Ch., Zhao S., Zhang Y. Characterization of heteroatom compounds in a crude oil and its saturates, aromatics resins, and asphaltenes (SARA) and non-basic nitrogen fractions analyzed by negative-ion electpospray ioniztoin fourier transform ion cyclotron resonance mass spectrometry. Energy and Fuels, 2010, vol. 24, no. 4, pp. 2545-2553.

11. Kamyanov V.F., Aksenov V.S., Titov V.I. Geteroatomnye komponenty neftey [Heteroatomic components of the oils]. Novosibirsk, Nauka Publ., 1983. 238 p.

12. Li T., Xu J., Zou R., Feng H., Li L., Wang J. Y., Stuart M.A.C., Guo X.H. Resin from Liaohe Heavy Oil: Molecular Structure, Aggregation Behavior, and Effect on Oil Viscosity. Energy Fuels, 2018, 32, no. 1, pp. 306-313.

13. Shchepalov A.A. Tyazhelye nefti, gazovye gidraty $i$ drugie perspektivnye istochniki uglevodorodnogo syrya [Heavy oil, gas hydrates and other perspective sources of hydrocarbon raw materials]. Nizhny Novgorod, Nizhegorodsky gosuniversitet Publ., $2012.93 \mathrm{p}$.

14. Gordadze G.N. Uglevodorody $v$ neftyanoy geokhimii. Teoriya $i$ praktika [Hydrocarbons in oil geochemistry. Theory and practice]. Moscow, RGU nefti i gaza im. I.M. Gubkina, 2015. 559 p.

15. Liu M., Zhang L.Z., Zhang C., Yuan S.H., Duan L.H. Transformation of nitrogen-containing compounds in atmospheric residue by hydrotreating. Korean Jounal of Chemical Engineering, 2018, vol. 35, no. 2, pp. 375-382.

16. Prado G.H.C., Rao Y., De Klerk A. Nitrogen Removal from Oil: a Review. Energy Fuels, 2017, vol. 31, no. 1, pp. 14-36.

17. Chen X.B., Liu Y.B., Li S.J., Feng X., Shan H.H., Yang C.H. Structure and Composition Changes of Nitrogen Compounds during the Catalytic Cracking Process and their Deactivating Effect on Catalysts. Energy Fuels, 2017, vol. 31, no. 4, pp. 3659-3668.

18. Chen X.B., Li T., Xin L., Yang Y.Q., Shan H.H., Yang C. H. Inductive Effect of Basic Nitrogen Compounds on Coke Formation During the Catalytic Cracking Process. Catal. Commun., 2016 vol. 74 , pp. $95-98$.

19. Wei Q., Wen. S.C., Tao X.J., Zhang T., Zhou Y.S., Chung K., $\mathrm{Xu}$ C.M. Hydrodenitrogenation of Basic and Non-Basic NitrogenContaining Compounds in Coker Gas Oil. Fuel Process. Technol., 2015, vol. 129, pp. 76-84.

20. Zhang J., Shan H., Chen X., Liu W., Yang C. Synergistic Process for High Nitrogen Content Feedstocks Catalytic-Cracking: A Case Study of Controlling the Reactions of Nitrogen Compounds in Situ. Industrial and Engineering Chemistry Research, 2014. vol. 53 , no. 14 , pp. $5718-5727$.

21. Bobkova T.V., Doronin V.P., Potapenko 0.V., Sorokina T.P., Ostrovsky N.M. The deactivating influence of nitrogen connections on transformations of model hydrocarbons and real raw materials in the conditions of catalytic cracking. Katalysis in Industry, 2014, no. 2, pp. 40-45. In Rus.

22. Isaev A.Ya., Allakhverdiev Z.S., Tagiev V.I., Mamedova G.F., Ismaylova M.M. Influence of quantitative maintenance of the ni- trogen bases in oil products on thermal stability of fuels. Oil processing and petrochemistry. Scientific and technical achievements and best practices, 2015, no. 2, pp. 10-12. In Rus.

23. Kong Jiao, Wei Xian-Yong, Yan Hong-Lei, Li Zhan-Ku, Zhao Mei-Xia, Li Yan, Zong Zhi-Min. Analysis of extractable basic nitrogen compounds in Buliangou subbituminous coal by positive-ion ESI FT-ICR MS. Fuel, 2015, vol. 159, pp. 385-391.

24. Li Peng, Zong Zhi-Min, Li Zhan-Ku, Wang Yu-Gao, Liu Fang-Jing, Wei Xian-Yong. Characterization of basic heteroatom-containing organic compounds in liquefaction residue from Sheunmu-Fugu subbituminous coal by positive-ion electrospray ionization Fourier transform ion cyclotron resonance mass spectrometry. Fuel Processing Technology, 2015, vol. 132, pp. 91-98.

25. Li S.J., Liu N.N. The transformation of basic nitrogen compounds in coker gas oil during catalytic cracking. Petroleum Science and Technology, 2017, vol. 35, no. 11, pp. 1141-1145.

26. Pevneva G.S., Voronetskaya N.G., Korneev D.S., Golovko A.K. Mutual influence of resins and oils in crude oil from the Usinskoe oilfield on the direction of their thermal transformations. Petroleum Chemistry, 2017, vol. 57, no. 8, pp. 739-745.

27. Sovremennye metody issledovaniya neftey: spravochno-metodicheskoe posobie [Modern methods of research of oils: reference benefit]. Ed. by A.I. Bogomolov, M.B. Temyanko, L.I. Khotyntseva. Leningrad, Nedra Publ., 1984. 431 p.

28. Okuno I., Latham D.R., Haines W.E. Type Analisis of Nitrogen in Petroleum Using Nonaqueous Potentiometric Titration and Litium Aluminum Hydride Reduction. Analitical Chemistry, 1965, vol. 37 , no. 1, pp. 54-57.

29. Golovko A.K., Kam'yanov V.F., Ogorodnikov V.D. High-molecular heteroatomic components of crude oils of the Timan-Pechora petroliferous basin. Russian Geology and Geophysics, 2012, vol. 53, Iss. 12, pp. 1374-1381.

30. Fergoug T., Bouhadda Y. Determination of Hassi Messaoud asphaltene aromatic structure from $\mathrm{H}-1$ \& $\mathrm{C}-13 \mathrm{NMR}$ analysis. Fuel, 2014, vol. 115, no. 1, pp. 521-526.

31. Khimichesky sostav neftey Zapadnoy Sibiri [Chemical composition of Western Siberia oils]. Ed. by G.F. Bolshakov. Novosibirsk, Nauka, Sibirskoye otdeleniye Publ., 1988. 288 p.

32. Peng P., Morales-Izquierdo A., Hogg A., Strauaz O. P. Molecular Structure of Athabasca Asphaltene: Sulfide, Ether, and Ester Linkages. Energy Fuels, 1997, vol. 11, no. 5, pp. 1171-1187.

33. Snowdon L.R., Volkman J.K., Zhang Z., Tao G., Liu P. The Organic Geochemistry of Asphaltenes and Occluded Biomarkers. Org. Geochem., 2016, vol. 91, no. 1, pp. 3-15.

34. Golovko A.K., Grin'ko A.A. Structural Transformations of Petroleum Resins and Their Fractions by Thermolysis. Petroleum Chemistry, 2018, vol. 58, no. 8, pp. 599-606.

35. Antipenko V.R. Termicheskie prevrashcheniya vysokosernistogo prirodnogo asfaltita: geokhimicheskie i tekhnologicheskie aspekty [Thermal transformations of a sulphur-rich natural asphaltite: Geochemical and technological aspects]. Novosibirsk, Nauka Publ., 2013. 184 p.

36. Sergun V.P., Cheshkova T.V., Sagachenko T.A., Min R.S. Chemical Composition of Petroleum from Krapivinskoe Oilfield (message 3). Bulletin of the Tomsk Polytechnic University. Geo Assets Engineering, 2017, vol. 328, no. 7, pp. 59-66. In Rus.

Received: 28 August 2019. 


\section{Information about the authors}

Natalia N. Gerasimova, Cand. Sc., associate professor, senior researcher, Institute of Petroleum Chemistry of Siberian Branch of the Russian Academy of Sciences.

Tatyana V.Cheshkova, Cand. Sc., researcher, Institute of Petroleum Chemistry of Siberian Branch of the Russian Academy of Sciences.

Evgenia B. Goluhskova, Cand. Sc., associate professor, National Research Tomsk polytechnic University.

Tamyana A. Sagachenko, Dr. Sc., chief researcher, Institute of Petroleum Chemistry of Siberian Branch of the Russian Academy of Sciences.

Raisa S. Min, Dr. Sc., head of the Laboratory of Heteroorganic Petroleum Compounds, Institute of Petroleum Chemistry of Siberian Branch of the Russian Academy of Sciences. 